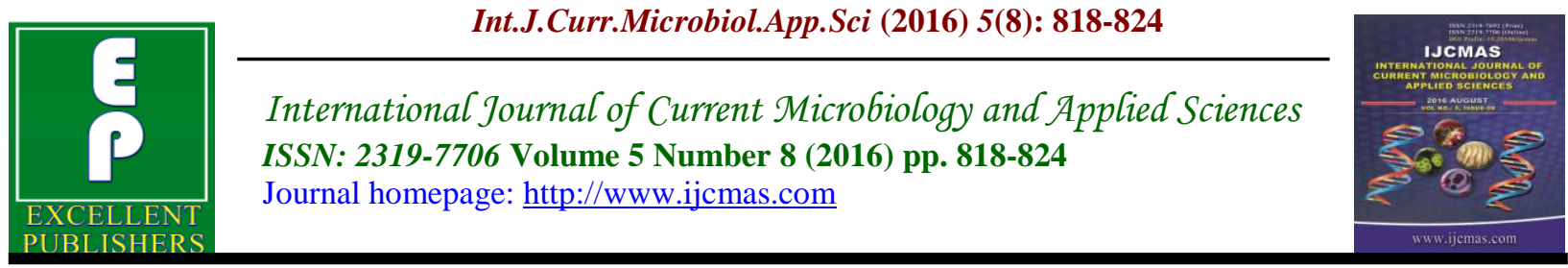

Original Research Article

http://dx.doi.org/10.20546/ijcmas.2016.508.091

\title{
Changes in the Oxidative Stress Biomarkers in Rat Liver Tissue Exposed to Cadmium and Protect with Hibiscus sabdariffa L. (Ro`ssle) Flower Extract
}

\author{
Khaled N. Al-kubaisy, Rania M. Al-Groom* and Adeeb Al- Amoush \\ Department of Biomedical Sci. Al-Balqa Applied University, Zarqa university \\ Collage-Zarqa-Jordan \\ *Corresponding author
}

Keywords

$\mathrm{Cdcl} 2$,

Hibiscus

sabdariffa extract, oxidative stress

biomarkers.

\section{Article Info}

Accepted:

18 July 2016

Available Online:

10 August 2016

\section{A B S T R A C T}

Cadmium chloride $\{\mathrm{Cdcl} 2\}$ is highly toxic chemical agent, it involves production of reactive oxygen species $\{\operatorname{Ros}\}$ and induce oxidative stress mainly attributed to the impairment of antioxidant defense mechanisms in the body. The study was designed to evaluate the possible role of antioxidant of Hibiscus subdariffa L.flower extract $\{\mathrm{HSSE}\}$ in the protection against $\mathrm{cdcl} 2$ - induced oxidative stress in rat liver tissue, specially changes in malondialdehyde $\{$ MDA $\}$ level, and enzymatic and non-enzymatic antioxidant. The following three experimental group were evaluated $\{1\}$ control, $\{2\} \mathrm{Cdcl} 2, \mathrm{Cdcl} 2+\mathrm{HSSE}$. Cdcl 2 caused significant decrease in reduced Glutahione $\{\mathrm{GSH}\}$ content, catalase $\{\mathrm{CAT}\}$ and superoxide dismutase $\{\mathrm{SOD}\}$ activities, as well as significant increase in malondialdehyde \{MDA\} level, indicate that cdcl 2 induced hepatotoxicity was mediated through oxidative stress. In contrast, HSE pretreatment significantly improved Cdcl 2 induced biochemical alterations. These result indicated that HSE has a protective action against Cdcl2 hepatotoxicity and suggest that HSE may find clinical application against a variety of toxins and drugs where cellular damage is a consequence of reactive oxygen species.

\section{Introduction}

There are more than 300 species of Hibiscus L. Hibiscus sabdariffa belong to the malvaceae family which is an annual herb growing in tropical and subtropical countries.

The calyx is the most important economic parts of the plants which is used in food and cosmetic industries as source of natural coloring agent (EL-meleigy, 1989). More over it has different ethnomedical properties and local soft drink. It was reported to be anticancer, antiseptic, depesia and fever (Duke, 1985), anti-inflammatory (Daffallah et al., 1996), antimutagenic (Farombi et al., 2005), is used in folk medicine to treat Diabetes, ulcer and jaundice (Yesiiada et al., 1995).

Hypolipidemic effects have been reported (Hirunpanich et al., 2006). Other studies properties of H.sabdariffa extract include cytotoxicity and genotoxicity (Rosa et al., 2007) and possess significant immunoprotective potential (OKoko et al., 2012). 
Preventing atherosclerosis and cardiovascular disease associates with Diabetes has been found (Farombi et al., 2007). Antimicrobial activity has also been documented (Al-hashimi, 2012; Jacob et al., 2011).

Previous phytochemical investigations of different part of this plant show the presence of phenolic compounds, flavonoids, protocatechuic acid, ascorbic acid and anthocyanins (Oboh et al., 2012) which found to possess wide pharmacological activities especially potent free-radical scavenging and antioxidant actions (Olusola et al., 2012; Liu et al., 2006, 2010). Furthermore liu et al., (2010) have demonstrated that HSE extract and anthocyanins were proved to be an effective hepatoprotective agent against carbon tetrachloride (Cc14) - induced liver injury. concerning the inhibitory effect of H.sabdariffa flower extract, Shawagfeh and Al-Kubaisy reported that when HSE was given prior to induction of hepatotoxicity by $>\mathrm{Cdcl} 2$ it was able to give protection against its harmful effects. Also it was found that HSE and anthocyanin exhibited significant protection against acetaminophen-induced liver damage. Kowalcyzyk et al., (2003) revealed that anthocyanins increase the resistance of hepatocytes to oxidation. Meanwhile, Delong et al., (2003) concluded that phytosteroids found in HSE have immune modulating function and aid in general health during cancer therapy. Moreover, Adeno et al., (2013) have indicated that the calyx extract of H.sabdariffa showed a beneficial effect against cis.platin - induces oxidative kidney damage.

Cadmium is one of the most dangerous occupational and environmental toxins. It is found in drinking water, atmospheric air and even in food. Cadmium is reported to be very toxic to biological systems. The liver, kidney, heart and testes are the most important target organs when considering $\mathrm{Cd}-$ induced toxicity because this heavy metal accumulates in these organs, for this reason many researchers are carried out to find natural compounds that help in the protection against $\mathrm{Cd}$ - induced toxicity with fewer or no side effects. Therefore the objective of the present study was to determine the protective actions of Hibiscus sabdariffa.L dried flower extract (HSE) against $\mathrm{Cdcl} 2$ - induced oxidative stress in rat liver tissue.

\section{Materials and Methods}

\section{Preparation of aqueous flower extracts}

Dried flowers of H.sabdriffa L.(Rossle) was obtained from herbal store -Amman- Jordan. It was identified at the biological sciences department at the university of Jordan and confirmed by comparing with those of known in the herbarium of the department. The dried flowers were ground into fine powder using electric dry mill.

A total of $100 \mathrm{gm}$ of the ground was soaked in $500 \mathrm{ml}$ of distilled water for 24 hour at 40 $\mathrm{c}$ temperature. The mixture was filtered with whatman filter paper No.1. The filtrate was dried at $40 \mathrm{c}$ temperature. The yield of HSE contain the following component; four major flavonoids phenolic acid (e.g. protocatechuic acid) and rich vitamin $\mathrm{C}$ content (Jarup et al., 1998).

Appropriate concentration of the extract was then subsequently made by dilution with distilled water into $250 \mathrm{mg} / \mathrm{kg}$ body weight and administered to the animals. The 250 $\mathrm{mg} / \mathrm{kg}$ extract was more effective than 500 $\mathrm{mg} / \mathrm{kg}$ in hepatic function which was well comparable with standard drug silymarin $(20 \mathrm{mg} / \mathrm{kg})$ (Lin et al., 2011). 


\section{Experimental Design}

A total of 18 healthy adult male albino rats weighing between (160-180 g) obtained from animal house - university of Applied sciences - Amman were used. The animals were maintained under standard conditions of humidity $50 \%$, temperature $(25 \pm 1$ c) with a $12 \mathrm{~h}$ light / dark cycle. All rats were allowed free access to food and water ad libitum. The rats were divided randomly into three groups of six rats each as follows:

Group I: receive as oil treated vehicle with saline control.

Group II: animal were administered Cdcl2; $4 \mathrm{mg} / \mathrm{kg}$ body weight in normal saline subcutaneously to induce liver injury.

Group III: Rats were treated with 250 $\mathrm{mg} / \mathrm{kg}$ body weight of (HSE) for one week and subsequently exposed to a single injection of Cdcl2 : 12 hour after the last (HSE) / vehicle treatment.

All experimental animals were handled according to the guidelines of the institutions animals ethical committee.

All chemicals used were of analytical grade, purchased locally.

\section{Sample Collection}

The rats were sacrificed under ether anaesthesia and their livers were excised washed with ice-cold saline and blotted to dryness. Sample of liver tissue were homogenized with ice-cold $(0.25 \mathrm{M}$ sucrose).

\section{Assessment of cellular macromolecule damage}

The level of lipid peroxidation (LPO) served as an index of the intensity of oxidative stress.
As malondialdehyde by (MDA) was determined in the liver tissue as described by (23) after incubation at $95{ }^{\circ} \mathrm{C}$ with thiobarbituric acid to generate pink color produced, which has absorption maximum at $532 \mathrm{~nm}$.

\section{Estimation of oxidative stress}

Estimation of catalase (CAT) activity in the liver homogenates were estimated by the method of (24) using a commercially available Kits obtained from calbiochem (USA) according to manufacturer's instruction.

Estimation of superoxide dismutase activity (SOD) was determined by the method of (25) using kits obtained from (calbiochem USA) according to manufacturer's instruction.

Estimation of total reduced glutathione (GSH) was determined in the liver homogenates by method of Ellman based on the development of yellow color when 5,5 dithio - bis 2-nitrobnzoic acid (DTNB) is added to the supernatant and was measured spectrophotometrically at $412 \mathrm{~nm}$ against reagent blank with no homogenate.

\section{Statistical analysis}

The values were expressed as mean \pm standard error of the mean for six animals in each group. Differences between group were assessed by the one way analysis of variance (ANOVA) using the SPSS version 10 software, and p-value $(<0.05)$ was regarded to be significant.

\section{Results and Discussion}

After experiment period of administration of single dose of $\mathrm{Cdcl} 2$, the lipid peroxidation (LPO) level in the liver homogenate of control and experimental rats is presented in Table (1). The effect of intoxication with 
$\mathrm{Cdcl} 2$ in the absence and presence of HSE extract supplementation on oxidative stress parameters, the data show in table (1) a significant elevation in the tissue lipid peroxidation biomarker (MDA) in $\operatorname{cdcl} 2$ intoxicated rats (group 2) versus normal control at $(\mathrm{p}<0.05)$. On other-'hand, significant decrease total reduce glutathione content in liver homogenate $(p<0.05)$ was recorded at period of treatment with $\mathrm{Cdcl} 2$. However the pretreatment with HSE (group 3) reversed the level of (MDA) to be near the normal control level and also resulted in a significant elevation in the content of $(\mathrm{GSH})$ at $(\mathrm{p}<0.05)$ when compared to $\mathrm{Cdcl} 2$ control (group2|) rat. Table (1) also present the status of antioxidant defense system. Administration of toxic dose of $\mathrm{Cdcl}_{2}$ produced marked depletion of the liver antioxidant enzyme, catalase and superoxide dismutase (group 2) animals. This depletion of antioxidant enzyme activities (CAT and SOD) was markedly prevented by administration of HSE in the Cdcl 2 treated rats. The results of present study confirm that the inhibition of oxidants production and restoration of enzymatic and nonenzymatic antioxidant status within control protected against these changes in dose dependent manner, indicates its potent antioxidant effect against oxidative stress induced by $\mathrm{Cdcl} 2$.

Many toxicants, including chemical and drugs induced liver injuries. Oxidative stress is typically result in an imbalance of oxidative homeostasis with excess production of reactive oxygen species (ROS) and relative deficiency of endogenous antioxidants. ROS induce lipid peroxidation. The lipid peroxidation is believed to play an important role in the pathogenesis of several disease such as cancer, diabetic, inflammation and liver injury. Many natural antioxidant play significant roles in the prevention and treatment of organic disease associated with oxidative stress.

Enormous reports suggest that oxidative stress, depletion of hepatic antioxidant system and increase in lipid peroxidation are the possible mechanisms of $\mathrm{Cdcl} 2$ (Beutler et al., 1963).

Values are given as mean \pm SEM for group of six animals each values are statically significant at $(\mathrm{p}<0.05)$. treat rats were compared with control. H.sabdariffa flower extract $+\mathrm{Cdcl} 2$ treated rats were compared with $\mathrm{Cdcl} 2$ treated rats. Cadmium, one of the most common toxic heavy metals can bind to metallothionein, but free $\mathrm{Cd}$ which has not combined with metallothionein, changes the enzyme activity and membrane structure by reacting with sulfhydryl group of the membrane, resulting in liver injury (Renugadevi et al., 2010; Foulkes, 1982) exposure to $\mathrm{cdcl}_{2}$ lead to a decrease in the activity of antioxidant enzymes, such as catalase and superoxide dismutase (Klassen et al., 1999). Cd also found depletes glutathione and sulfhydryl protein leading to increased lipid peroxidation and enhanced intracellular oxidized states.

In the present study, the rats treated with $\mathrm{Cdcl}_{2}$ showed a significant hepatic damage, as malondialdehyde (MDA), the biomarker of lipid peroxidation, generation of free radicals probably because of the alteration in normal homeostasis of the body resulting in oxidative stress. Also show depletion in the reduced glutathione (GSH) content in liver tissue, GSH, is an early consequence of oxidative stress. Acute $\mathrm{Cdcl}_{2}$ damage could significantly decrease the expression of antioxidant enzymes in the liver cells such as catalase and superoxide dismutase (SOD). GSH-related enzymes play in detoxifying and antioxidant role in metabolizing xenobioties through conjugation with glutathione or reduction of free radicals. 
Table.1 effect of cdcl 2 and flower extract of H.sabdariffa on lipid peroxidation (MDA) level reduced glutathione $(\mathrm{GSH})$ content and antioxidant enzyme activities of hepatic cell in rats groups.

\begin{tabular}{|l|l|l|l|}
\hline Parameters & Control & Cadmium $($ cdcl2) & Cdcl2+extract \\
\hline MDA nmol/g wet tissue & $139.87 \pm 1.28$ & $181.20 \pm 1.17^{*}$ & $143 \pm 3.10^{*}$ \\
GSH nmol/g wet tissue & $1.52 \pm 0.17$ & $1.02 \pm 0.07^{*}$ & $1.38 \pm 0.13^{*}$ \\
CAT u/ml & $118.41 \pm 2.12$ & $69.71 \pm 1.33^{*}$ & $109.42 \pm 0.18^{*}$ \\
SOD u/ml & $26.75 \pm 1.14$ & $14.88 \pm 1.28^{*}$ & $22.37 \pm 0.66^{*}$ \\
\hline
\end{tabular}

Many plants derived natural products have the potential to be hepatoprotective against various toxic chemicals and drugs, therefore they can be used to treat acute and chronic liver disease. The challenge is to identify the most promising compounds and evaluate their protective mechanism. The phytochemical analysis of the extract from flower of $H$. Sabdariffa showed the presence of phenolic compounds, four major flavonols, protocatechuic acid, anthocyanin and vitamin C. Since the antioxidant and hepatoprotective activities of certain flavonols from plant origin have already been established (Koyu et al., 2006). The relatively high polyphenol content of 16 $\mathrm{mg} / \mathrm{ml}$ observed for the crude extract of $H$. Sabdariffa flowers is indicative of potential of antioxidative properties and the DPPH radical scavenging activity of HSE was more than vitamin C (Olusola et al., 2012). Moreover, AL-Hashimi (2000) reported that the crude extract of HSE has total phenolic content $(77-87) \mathrm{mg} / \mathrm{g}$.

HSE co-supplementation in our study significantly restored the activities of hepatic oxidative stress markers to considerable extent (table 1). this protective action might possibly be due to its effect on preserving the cellular membrane of hepatocytes from breakage by reactive metabolites, thereby restoring the status of these markers, it has been found that HSE to have excellent scavenging ability on free radicals which was well comparable with standard drug silymarin $(20 \mathrm{mg} / \mathrm{kg})$.
Shwaghfah and AL-Kubaisy have revealed that the aqueous extract of HSE showed a potent beneficial effect against $\mathrm{Cdcl}_{2}$ induced liver damage by protecting the liver biochemical markers as well as emphasizing its antioxidant potential.

Further, dried flower extract of HS was reported to be highly effective in scavenging free radicals and thereby offering hepatoprotection against $\mathrm{Ccl}_{4}$,paracetamol and phenobarbitone - induced hepatotoxicity in rats (AL - Hasimi, 2012) respectively.

From the data observed in the present study thus strongly confirms that the dried flower extract of HS might have scavenged detoxified the free radicals and improve the activities of hepatic oxidative stress and antioxidant status. Therefore, HSE could be useful as a hepatoprotective agent against chemicals and drugs-induced oxidative damage of liver in vivo.

\section{Acknowledgment}

Author is thankful to dean of college for infrastructure and all other essential facilities for the successful completion of this work.

\section{References}

Adedyo, O., Ademilay, Ganiyu Oboh. Oluwaseun, J. et al., 2013. Anthocyanin cis - platin - induced nephrotoxicity and 
oxidative stress in rats. inter, J. Biomed Sci., 9(4): 243 - 248.

AL-Hasimi, A. 2012. Antioxidant and antibacterial activities of H.sabdariffa extract. Afr. J. Food Sci., 6(21) : 506 511.

Al-hashimi, A. 2012. antioxidant and antibacterial activities of Hibiscus Sabdariffa extract. afr. J. Food sci., 6(21) : 506 - 511.

Beutler, E., Duron, O. and Kelly, M.B. 1963. improved method for the determination of blood glutathione. J. Lab. Clin. Med., $61,882-888$.

Daffallah, A.A. and Mustafa, Z. 1996. investigation of anti- inflamm - altory activity of Acacia notitoca and Hibiscus Sabdarriffa. Amer. J. Clin. Med., 24 : 263-269.

Delong, A., Plat, J., Mensike, B.P. 2003. Metabolic effects of plant sterols and stanols. J. Nutr. Biochem. Rev., 14(7): 362-369.

Duke, J. 1985. A. Handbook of medicinal herbs, $7^{\text {th }}$ edition Edinburgh. living stone group LTd. pp $228-229$.

EL-meleigy, S. 1989. Physiological studies on rossele plant, Hibiscuss sabdariffa L. ph. D. thesis. Ain shams university - Egypt.

Farombi, E.O., and Fakoya, A. 2005. Free radicals scavenging and antigenotoxic activities of natural phenolic compounds in dried flowers of Hibiscus sabdariffa. Mol. Nut. And Food Res., 49(12) : 1120 1128.

Farombi, E.O. and Ige, O.O. 2007. hypolipidemic and antioxidant effects of ethanolic extract from dried calyx of hibiscus sabdariffa in alloxan - Induced diabetic rate. Fundem. Clin. Pharmacol., 21(6): $601-609$.

Foulkes, E.C. 1982. Biological roles of metallothionein. N.Y. Elsevier Holland.

Hirunpanich, V., Utaipat, A., morales, N.P., Bunya praphatsara, N. and et al. 2013. pocholestrolemic and antioxidant effects of aqueous extract from dried calyx of hibiscus sabdariffa in hypercholestrolemic tats, $J$.
Ethnopharmacol., 103: 252-260, Inter, J., pharmacognosy and phytochem., 28(1): 1127-1131.

Jacob, S.J.P. and Shenbagaraman, S. 2011. evaluation of antioxidant and antimicrobial activities of the selected green leafy vegetables. Inter. J. Pharm. Tech. Res., 3(1): 148-152.

Jarup, 1. Berglund, M. Elinder, C.G., Nordberg, G. et al. 1998. Health effects of cadmium exposure: review of the literature and a risk estimate. Scand. J. Word Environ. Health., (24) 1-51.

Johansson, L.H., Borg, L.A.H. 1988. A spectrophotometric method for determination of catalase activity in small tissue samples. Anal. Biochem., 174: 331 -336 .

Jurczuk, M., brzoska, M.M., Moniuszko Jakoniuk, J. et al. 2004. Antioxidant enzymes activity and lipid peroxidation in liver and kidney of rats exposed to cadmium and ethanol. Food. Chem. Toxicol., 42: 429 - 438.

Kakkar, P., Dos, B., Viswanathan, P.N. 1984. A modified spectrophotometric assay of superoxide dismutase. ind. J. Biochem. Biophys., 21: 130 - 132.

Klassen, Lcd. Liu, J. Choudhuri, S. 1999. Metallothionein: An intracellular protein to protect against cadmium toxicity. Ann. Rev. Pharmacol. Toxicol., 39: 267 - 94.

Kowalczyk, E., kopff, A. Fijalkowski, P., Kopff, M. et al. 2003. Effect of anthocyanins on selected biochemical parameters in rats exposed to cadmium, Acta biochem. Pol., 50(2): 543-548.

Koyu, A., Gokicmen, A., Ozguner, F. et al. 2006. Evaluation of the effects of Cadmium on rat liver. Mol. Cell Biochem., 284: 81-85.

Lin, H., H. Chen, J., H. Wang, C.J. 2011. Chemopreventive properties and molecular mechanisms of bioactive compounds in $H$. sabdariffa. A review : Curr. Med. Chem., 18(8): 1245-1254.

Liu, J.Y., chen, C.C., wang, W.H., Hsu, J.D. et al. 2006. protective effects of Hibiscus Sabdariffa extract on $\mathrm{CCl}_{4}$ induced liver 
fibrosis in rats. Food chem. Toxicol., 44(3) : $336-343$.

Liu, L., C. wang, C., J. Lee, C.C,, SU, S.C., et al. 2010. Aqueous extract of Hibiscus Sabdariffa $L$, decelerates acetaminophen - induced acute liver damage by reducing cell death and oxidative stress in mouse experimental models. J. SC. : Food Agric., 90(2) : 329 - 337.

Mirani, N., Ashraf, N.J., Siddque, J., Rub, A. 2012. protective effect of Rutin against cadmium - induced hebatotoxicity in swiss albinomice. L. Pharmacol. Toxicol., 7(3): 150 - 157.

Oboh, H.A. and Okhai, E.O. 2012. Antioxidant and free radical scavenging abilities of some indigenous Nigerian drinks. N, J. basis and Appl, Sci., 20(1) : 21-26.

Ohkawa, N.K., Ohishi and Yagi, K. 1979. Assay for lipid peroxides in animal tissue by theiobarabituric acid reaction. Anal. Biochem., $95: 351$ - 358.

OKoko, T. and Freb, D. Hibiscus Sabdariffa extract activities on cadmium mediated alteration of human cell viability and activation. Asian pacific J. tropical Med., 5(1): 33-36.

Olusola, A.O., Bada, S.O., Obi, F.O. 2012. Comparative study on the effect of Hibiscus Sabdariffa calyx anthocyanin and ascorbate on 2,4 Dinitrophenyl hadrazzine - induced damage in rabbits. Amer. J. Biochem., 2(2) : 1-6.

Pieta, P.G. 2000. Flavonoids as antioxidants. J. Nat. Prod., 63(7): 1035 - 42.
Renugadevi, J. and prabu, S.M. 2010. Cadmium - induced hepatotoxicity in rats and protective effect of naringenin. Exp. Toxicol. Pathol., 62(2) : $171-181$.

Rosa, R.M., Moura, D.J., Melecchi, M.I., dos santos, R.S., et al. protective effects of hibiscus sabdariffa L- methanolic extract to V79 cells against cytotoxicity and genotoxicity induced by hydrogen perpxide and tert-butyl hydroperoxide toxicol in vitro, 21 (8) : $1442-1462$.

Shwagfeh, M.T., Al-kubaisy, K.H. protective effect of aqueous flower extract of $H$. sabdariffa in $\mathrm{CdCl}_{2}$ - induced acute liver damage in rats.

Sunilson, J.A., Jayaraj, P., mohan, M.S., Kumari, A.A. et al. 2008. Antioxidant and hepatoprotective effect of the roots of H.esculents. Inter. J. Green Pharmacy, 2(4) : $200-203$.

Ubani, C.S., Joshua, P.E., Anieke, U.C. 2011. Effects of aqueous extract $H$. sabdariffa calyces on liver marker enzymes of phenobarbitone - induced adult albino rats. J. Chem Pharm. Res., 3(4) : 528 537.

Usoh, I.F., Itemobang, S.E., Etim, O.E., et al. 2011. Antioxidant and hepatoprotective effects of dried flower extract of $H$. sabdariffa on rats treated with $\mathrm{CCl}_{4} . J$. Appl. Pharmaceutical Sci., 2(8): 156-59.

Yesiiada, E., Honda, G., sezik, E., tabata, M., et al. 1995. Traditional medicine in turkey, V. Folk medicine in the Inner Taurus mountain, J. Ethenopharmacol., 463: 133-152.

\section{How to cite this article:}

Khaled N. Al-kubaisy, Rania M. Al-Groom and Adeeb Al- Amoush. 2016. Changes in the Oxidative Stress Biomarkers in Rat Liver Tissue Exposed to Cadmium and Protect with Hibiscus sabdariffa L. (Ro`ssle) Flower Extract. Int.J.Curr.Microbiol.App.Sci. 5(8): 818-824. doi: http://dx.doi.org/10.20546/ijcmas.2016.508.091 